\title{
Early Warning System triggers in Intensive Care Unit after receiving Intrathecal Morphine: A Retrospective Analysis.
}

James Richard Skelly Skelly ( $\sim$ jamesrichardskelly@gmail.com )

National Maternity Hospital https://orcid.org/0000-0003-2698-6739

Wouter $\mathrm{R}$ Jonker

Sligo University Hospital

\section{Research}

Keywords: Intensive care, Intrathecal morphine, Neuraxial Analgesia, Post-operative analgesia, Spinal Morphine, Subarachnoid, Early Warning Score

Posted Date: August 30th, 2021

DOI: https://doi.org/10.21203/rs.3.rs-829425/v1

License: (c) (i) This work is licensed under a Creative Commons Attribution 4.0 International License. Read Full License 


\section{Abstract}

\section{Background}

Neuraxial analgesia, including intrathecal morphine(ITM) administration, provides excellent analgesia in the post-abdominal surgery setting. As a corollary, such patients are commonly admitted to HDU/ICU for post-operative monitoring, and as such, bed availability can curtail its use. Reluctance to ward based postoperative care for this cohort is evident. Ward based postoperative care could benefit post-operative analgesic management.

\section{Methods}

We reviewed post-operative vital signs constituting the Irish National Early Warning System (INEWS), for general surgical patients admitted to our ICU after ITM administration, as would be undertaken at ward level. Data analysis for a period between January 2015 and August 2018. Inclusion criteria included: abdominal surgery; preoperative ITM and ICU admission post-operatively. Data for the initial 24 hours of ICU admission were obtained, including: AVPU score; respiratory rate(RR); fraction inspired oxygen $\left(\mathrm{FiO}_{2}\right)$; arterial oxygen saturation( $\left(\mathrm{SpO}_{2}\right)$; heart rate( $\left.\mathrm{HR}\right)$; systolic blood pressure(sBP). Additional measurements include recorded: ITM dose, age, weight, ASA grade, APACHE II Score, visual analogue pain scale scores, analgesic requirements.

\section{Results}

Thirty patients were included. The ITM dose was $548.3 \pm 28.2 \mathrm{mcg}(\mathrm{mean} \pm \mathrm{SD})$. Mean maximum constituent INEWS Scores were: $1.7 \pm 0.2(\mathrm{RR}) ; 1.5 \pm 0.2\left(\mathrm{SpO}_{2}\right) ; 1.6 \pm 0.3(\mathrm{AVPU}) ; 1.1 \pm 0.2(\mathrm{HR}) ; 2.0 \pm 0.2(\mathrm{sBP})$ giving a mean maximum total INEWS score of $4.9 \pm 0.3$. Four subjects scored $\geq 7$. No patient had INEWS de-escalated for supplemental oxygen and as such the addition of 3 NEWS points for oxygen supplementation would be applied to $96.7 \%(n=29)$ of patients.

\section{Conclusions}

The current study demonstrates that patients receiving these doses of ITM can exhibit high INEWS scores which would trigger escalation as outlined by the INEWS scoring system if located on a level 1 ward.

\section{Background}

Analgesia in the post-abdominal surgery setting is of paramount concern to the peri-operative physician. Adequate analgesia reduces the incidence of morbidity in the form of thrombo-embolic disease, hospital acquired pneumonia and myocardial infarction (1), and as such contributes to reduced mortality. Neuraxial analgesia, including intrathecal morphine (ITM) administration, is proven to provide the gold standard of pain relief in this setting and as such access to these techniques must be optimised. The potential side effects (hypotension, sedation, pruritis, respiratory depression) after IT opioids, in particular 
the risk of respiratory depression, requires increased frequency of observations as recommended by the American Association of Regional Analgesia (2) practice guidelines.

Common practice in many institutions is for the admission of such patients to a High Dependency or Intensive Care unit (3) for post-operative monitoring. Currently patients are admitted to Intensive Care Unit in our institution for post-op management. This is due to the absence of a High Dependency Unit in this hospital. Patients that received ITM doses of less than $200 \mathrm{mcg}$ for caesarean sections are cared for on the maternity ward post-operatively and monitored accordingly. Respiratory depression is found more frequently after higher doses of ITM $(>300 \mathrm{mcg})(4,5)$. The same authors, in a multicentre study involving 188 patients undergoing orthopaedic surgery demonstrated that the use of rescue opioids was significantly lower for $72 \mathrm{~h}$ in a group given $200 \mu \mathrm{g}$ of intrathecal morphine than among those who received $100 \mu \mathrm{g}(P<0.05)$ and in both groups with respect to the placebo group $(P<0.0001)$. The monitoring required for this group of patients are currently not available outside ICU in our institution (6).

We aimed to determine the number of patients admitted to our ICU after ITM administration as well as the incidences of side-effects as defined by the Irish National Early Warning System (INEWS).

\section{Methods}

Interrogation of the ICU digital records (IntelliSpace Critical Care and Anesthesia H.02.01) system for the period 01/01/2015 and 31/08/2018 was performed to identify patients for the study. Records were searched for the terms "spinal", "Intrathecal", "SAB" and "Subarachnoid Block". All records containing these terms were reviewed to elucidate relevance for inclusion in the current study. Patient records that failed to meet the inclusion criteria were excluded from analysis.

Patient selection was based on meeting the following inclusion criteria:

1. Patients must have undergone abdominal surgery

2. Patients must have received preoperative intrathecal morphine (ITM)

3. Patients' must have been admitted to the Intensive care Unit post-operatively

Exclusion criteria:

1. Post-op Caesarean section patients

2. Patients that received intrathecal fentanyl only

3. Patients that received epidural opioids

Data pertaining to the initial 24 hours of the patients' ICU stay were obtained from digital ICU records meeting the inclusion criteria. This included: age, weight, ASA grade, APACHE II Score, existing respiratory co-morbidities, surgical procedure, emergent or elective surgery, AVPU score, respiratory rate, fraction inspired oxygen (FiO2), non-invasive arterial oxygen saturation (SpO2), heart rate, systolic blood pressure, visual analogue pain scale scores $(0-10)$, additional analgesic requirements, interventions required (e.g. 
IV naloxone, vasopressors etc.), sedation requirements and indication for ICU admission. Pre-operative intrathecal morphine doses were obtained from the paper anaesthetic records.

Using data for AVPU score, FiO2, Sp02, heart rate and systolic blood pressure, calculation of the Early Warning Score (using Irish National EWS charts) were calculated for time points during the initial 24 hours of each patients' ICU stay. The interval between calculated EWS was dependent on the intervals between the initial vital sign recordings as undertaken by the ICU staff. Interval ranged from a minimum of 5 minutes to a maximum interval of 1 hour between calculated EWS scores.

Records were tabulated and analysed using Microsoft Excel (Version 15, Microsoft Corporation, Redmond, USA).

Between the dates of 1/8/18 and 15/8/18 a national (Republic of Ireland) critical care unit (level 2 and 3, $n=25)$ survey was undertaken. Critical care clinical nurse managers were asked if their institutional practice mandated that general surgical patients, who receive intrathecal morphine prior to surgical intervention, were required to be admitted to the intensive care/ high dependency units post-operatively. We also collated data from this survey related to the existence of acute pain teams within each hospital.

\section{Results}

A search of the ICU digital database, using keyword "spinal", "Intrathecal", "SAB" and "Subarachnoid Block", initially identified 134 patients. After application of inclusion and exclusion criteria 104 patients were excluded from analysis, 38 were post-op Caesarean section patients, 63 patients received intrathecal fentanyl only and 3 patients received epidural opioids. After review of each case, 30 patients met the inclusion criteria (Fig. 1.).

Patient demographics (Table 1.) were as follows: Age $71.6 \pm 10.8$ years (mean \pm SD); weight $69.6 \pm$ $15.1 \mathrm{~kg}$; ASA grade $2.7 \pm 0.5$; APACHE II score $13.3 \pm 4.9$ with $53 \%(n=16)$ of procedures classed as emergency. Reason for admission to ICU was recorded on the digital ICU system as Post-intrathecal morphine administration monitoring in $83.3 \%(n=25)$ of subjects and maintenance of invasive ventilation accounted for $16.7 \%(n=5)$ of the cohort. No patients required intubation within the ICU in the $24 \mathrm{hr}$ post-operative period. The mean length of stay was $1.9 \pm 0.2$ days

The mean ITM dose administered was $548.3 \pm 154.5 \mathrm{mcg}$ (Range: $200-1000 \mathrm{mcg}$ ) equating to $8.1 \pm$ $2.8 \mathrm{mcg} / \mathrm{kg}$.

Within the initial $24 \mathrm{hr}$ post-operative period the mean maximum pain scores recorded were $2.5 \pm 2.9$. No additional analgesics were administered in $40 \%(n=12)$ of the cohort. Paracetamol was administered in $60 \%(n=18)$ of the cohort. Addition post-operative analgesics administered were: NSAIDs $10 \%(n=3)$; Opioids (IV Morphine/Oxycodone) 16.7\% [ $n=5$, (PCA $n=3$, stat dose $n=2)$ ]; Local anaesthetic wound infiltration $6.7 \%(n=12)$ and clonidine $6.7 \%(n=2)$. These numbers pertain to administered doses and not prescribed medications. 
Mean minimum respiratory rate (RR) of $9.1 \pm 2.3$ attaining a mean maximum RR EWS of $1.7 \pm 1.2$ (Fig. 2). Thirteen ( $43 \%$ ) subjects had minimum RR of $\leq 8$ breaths per minute equating to an individual Respiratory EWS of 3 . Of the subjects with RR $\leq 8$, the mean time to RR $\leq 8$ was $313 \pm 292$ minutes and the time to last recorded $R R \leq 8$ within the initial $24 \mathrm{hrs}$ was $769 \pm 227$ minutes. One patient required naloxone administration (patient received $700 \mathrm{mg}$ ITM equating to $8.14 \mathrm{mcg} / \mathrm{kg}$ ). Other respiratory interventions included the administration of short acting bronchodilators in two patients with the addition of a longacting bronchodilators in 1 of these patients. Most $(96.7 \%, n=29)$ of the patients required supplemental oxygen within the initial $24 \mathrm{hrs}$ post-operative period. Figure 2 presents the mean \pm SD values for each domain within the EWS calculation as well as that of the total EWS score for the population.

The mean maximum $\mathrm{FiO} 2$ was calculated as $0.45 \pm 0.20$ with mean minimum $\mathrm{SpO} 2$ values of $93.2 \pm$ $3.0 \%$. Mean maximum SpO2 EWS were $1.5 \pm 1.5$. A nadir SpO2 of $\leq 91 \%$ equating to a SpO2 EWS of 3 occurred in $23 \%(n=7)$ patients. No patient had EWS de-escalated for supplemental oxygen.

The mean maximum AVPU EWS score was $1.5 \pm 1.5$ with $50 \%(n=15)$ of patients alert throughout, $36.7 \%$ $(n=11)$ of patients scoring the value of 3 for lowest consciousness recorded as rousable to voice (2 of these patients were initially sedated for endotracheal tube tolerance on arrival in the ICU), $10 \%(n=3)$ of patients scored a EWS of 3 for lowest consciousness recorded as rousable to pain (2 of which were sedated for endotracheal tube tolerance on arrival in the ICU) and 3.3\% $(n=1)$ of patients scoring a EWS of 3 for lowest consciousness recorded as unresponsiveness, this was sedated for tube tolerance on arrival in the ICU. Excluding sedated patients 10 scored an AVPU EWS of 3, 9 of which had a lowest consciousness of rousable to voice and patient was rousable to pain only.

The mean maximum heart rate (HR) was $102 \pm 16 \mathrm{bpm}$ equating to a mean maximum HR EWS of $1.1 \pm$ 0.9 with $13.3 \%(n=4)$ of the cohort attaining a HR of $\geq 131 \mathrm{bpm}$ and a EWS of 3 . One patient scored a EWS of 1 for HR between 41-50bpm. The average minimum systolic blood pressure (BP) was $90.2 \pm$ $14.0 \mathrm{mmHg}$ which equates to a mean maximum systolic BP EWS of $2.1 \pm 0.9$. Twelve subjects scored a systolic BP of $\leq 90 \mathrm{mmHg}$ and attaining a systolic BP EWS of 3 . No subjects BP scored a EWS for high BP. Cardiovascular interventions included: Crystalloid bolus $36.7 \%(n=11)$; Colloid bolus $13.3 \%(n=4)$; noradrenaline infusion $13.3 \%(n=4$, one of which was sedated); phenylephrine infusion $6.7 \%(n=2$, neither sedated); IV magnesium 33.3\% ( $n=10)$; digoxin 3.3\% $(n=1)$; Amiodarone Infusion $3.3 \%(n=1)$ and Beta Blockade 3.3\% $(n=1)$.

The mean maximum total EWS score for the cohort was $4.9 \pm 1.6$ with 4 subjects scoring a maximum total EWS of $\geq 7$ without the addition of 3 additional EWS points for oxygen supplementation. This required immediate review by a doctor of minimum registrar grade, continuous patient monitoring and formulation of a plan to move the patient to higher level care, as per EWS escalation policy.

The national critical care unit survey showed out of the 25 units; $96 \%$ of these hospitals provided intrathecal morphine administration prior to general surgical cases with one exception within the cohort due to patient case load. $50 \%(12 / 24)$ of hospitals mandated ICU/HDU admission post-intrathecal morphine administration. $54 \%(13 / 24)$ of these hospitals have an acute pain team. $45 \%(5 / 11)$ without 
acute pain teams discharge patient from PACU to level 1 surgical wards post-intrathecal morphine administration.

\section{Discussion}

The first study on opioids for intrathecal anaesthesia was carried out by Racoviceanu-Pitesti, a Romanian surgeon, who presented his experience in Paris in 1901 (7). Since then opioids have become the most popular adjuvants for intrathecal anaesthetic administration (8) and are widely used as a single dose to provide post-operative analgesia (4). The beneficial analgesic effects of ITM administration have become well recognised (9-15) and is considered by some to be the gold standard for single-dose neuraxial opioid due to its postoperative analgesic efficacy and prolonged duration of action (16). ITM provides decreased pain intensity and for 24 hours post-operatively with decreased adjuvant analgesic requirements, being particularly evident after abdominal surgery (17). It has also previously been proven as superior to opioid based patient-controlled analgesia (PCA) as a form of post-operative pain relief (12, 18). However, irrespective of its superiority, other authors argue that an unfavourable risk:benefit profile makes the intrathecal application of morphine an undesirable technique (19). The possibility of reduced respiratory drive with accompanying hypoventilation, central apnoea and desaturation is a known side effect (20), especially when higher doses of ITM (>300 $\mathrm{mcg})$ are used (21).

Even with numerous studies exhibiting the longevity of ITM for post-surgical analgesia, there remains a lack of consensus or evidence to create a linear dose response relationship for either the beneficial analgesic effects, or the harmful side effects of ITM (17). The magnitude of analgesia or the optimal dose of ITM has remained elusive with several studies failing to reach consensus ( $(14,22-26))$. A ceiling of analgesic effect has been suggested above which the risk benefit ratio begins to become unfavourable. Rathmell et al (21) in their review of over 1400 articles concluded that the analgesic effects of ITM become overshadowed by the side effect profile above a dose of $300 \mathrm{mcg}$, and this has been shown specifically in relation to the general surgical cohort (17). In a large meta-analysis of studies on spinal anaesthesia it was shown that ITM doses of $<300 \mathrm{mcg}$ were not associated with higher rates of respiratory depression than placebo (5). Giovannelli et al performed a meta-analysis on studies on spinal anaesthesia and ITM administration, they found no significant increase in the incidence of respiratory depression in cohorts who received $<300 \mathrm{mcg}$ ITM versus sham (4). In addition to this, Koning et al in 2018 also showed, in a cohort of 56 patients who underwent Laparoscopic Segmental Colonic resection, that application of $300 \mathrm{mcg}$ ITM was associated with a significant decrease in opioid use and lower pain scores on postoperative day one and that there were no differences in adverse events, time to mobilization, fluid administration, or patient satisfaction (13). As well as this they showed that median time to discharge was significantly decreased in the ITM group.

This dose recommendation has been replicated in the orthopaedic setting with 200-300mcg ITM being recommended for total knee replacement by Hassett et al (27). Evidence would appear to strengthen the case for the above aforementioned dose of $300 \mathrm{mcg}$ intrathecal morphine as a safe and effective dose 
with an acceptable side effect profile and as such most probably the optimum dose with regards to the risk:benefit ratio of ITM administration.

However, in one case study, in which a patient was inadvertently administered $4000 \mathrm{mcg}$ of ITM, the patient was monitored for 180 minutes after administration and a respiratory rate between 12-16 breaths per minute was noted. This patient was subsequently treated with naloxone after becoming diaphoretic and began vomiting (28). In this case, there was no respiratory depression and naloxone was administered due to nausea and vomiting and as such cannot be used to assess the effects of this dose on respiratory status after 3 hours.

Previously work in relation to weight based dosing of ITM in the setting of spinal surgery has indicated that doses of $2-4 \mathrm{mcg} / \mathrm{kg}$ (eg $75 \mathrm{~kg}$ gives a range of $150-300 \mathrm{mcg}$ ) yielded effective post-operative analgesia with minimal side effects and thus these patients could be managed at ward level (24). In this current study a mean dose of more than double this $(8.12 \pm 0.53 \mathrm{mcg} / \mathrm{kg})$ was administered which may account for the incidence of respiratory depression observed. The maximum dose administered in our study was $19.23 \mathrm{mcg} / \mathrm{kg}$ which resulted in a minimum respiratory rate of 10 breaths per minute and the lowest respiratory rate observed in this study was 5 breathes per minute in a patient who received $10.71 \mathrm{mcg} / \mathrm{kg}$ ITM. Both of these patients received only paracetamol as further analgesia in ICU. These doses are relatively high in comparison to much of the literature however this lack consistency in dose related responses echos that of much of the literature and as such may negate the use of a dose per weight approach to ITM administration

Incidence of respiratory depression has been shown to peak 8-10 hours after the application of ITM (29). This is the major overriding influence on the destination of these patients post-operatively. With the pressure on HDU/ICU beds and lack of continuous monitoring on the wards this leads to ward based care being the only available for post-operative care and the option of ITM administration is obviated.

The ASRA practice guidelines (2) recommends that the lowest efficacious dose of neuraxial opioids are administered as well as that all patients receiving neuraxial opioids should be monitored for adequacy of ventilation (e.g. respiratory rate, depth of respiration), oxygenation (e.g. pulse oximetry when appropriate) and level of consciousness. Previously there has been little consensus on the definition of respiratory depression. Ko et al. reviewed 96 studies of which forty-four did not define respiratory depression, despite referring to the state, and the subsequent studies used a range of parameters including respiratory rate, with or without the combination of arterial blood gas values and the use of naloxone (30).

For the purposes of this study we decided for practicality to use the Irish Health Service Executive (HSE) National Early Warning Score (INEWS) parameters as a scale of vital sign deterioration, including respiratory depression(31). In this standardised vital sign record sheet nursing staff are mandated to contact medical staff once certain parameters are met. For respiratory rate a value of $\leq 8$ breaths per minute is considered to warrant an immediate medical review and as such this value was taken as our threshold definition of respiratory depression. Since the study was carried out a new early warning score system, INEWS V2(32), has been introduced which is identical apart from its addition of confusion to the 
AVPU scale (ACVPU: C = confusion). As such, results described herein may differ if the study was repeated with the revised INEWS parameters.

Early warning scores have been developed to facilitate early detection of deterioration by categorising a patient's severity of illness and prompting nursing, and other healthcare professionals, to request a medical review at specific trigger points, utilising structured communication tools whilst following a definitive escalation plan. These are collated on the INEWS chart (Fig. 3).

In addition to this, the completion of neurological (e.g. Glasgow coma scale), intake-output etc. observations must be carried out whenever indicated with their own guidelines of escalation. The mean INEWS of 4.9 in our study group (after ITM doses of average $549 \mathrm{mcg}$ ), requires INEWS escalation protocol (Fig. 4.) to be activated.

This confirms the potential need for continuous monitoring and 1 hourly observation similar to what is recommended by ASRA (2). With appropriate staff ratios, education and monitoring equipment this could potentially be provided on ward level. EWS of equal or more than seven requires nurse in charge and team Registrar or On-call Consultant, to be informed and immediately review the patient and applying continuous monitoring. The recommended response is that the reviewing doctor should consider activating Emergency Response System and plan transfer to higher level of care.

Establishing post-operative monitoring for patients after ITM doses of $>300 \mathrm{mcg}$ on general surgical wards will be challenging. The additional work load would require nursing and primary staff training and may benefit from the existence of an anaesthesiology led Acute Pain Service.

In the obstetric setting, ITM has been shown to provide better post LSCS analgesia than both patient controlled epidural analgesia (PCEA) and post LSCS epidural morphine bolus of $3 \mathrm{mg}$ (33). Within this field, more conservative doses of intrathecal morphine (up to $200 \mathrm{mcg}$ ) are commonly used in elective and emergent caesarean section (CS) with post-operative monitoring occurring primarily at ward level without the requirement for escalation to HDU/ICU. In this cohort, evidence indicates that doses of $250-300 \mathrm{mcg}$ are safe in this setting without hypoventilation affecting patient care (34). That being said the consensus remains that these patients require continual monitoring for the 24 hours following ITM administration (35).

Evidently, the obstetric population is unique, without, in the most part, the common co-morbidities and age profile exhibited by the general surgical population. As such care must be taken with patients of higher ASA grade/APACHE Scores and as is current practice, post-operative destination must be influenced by the patients' pre-operative condition. As was evidenced in this study patients presenting for surgery with higher ASA grade/APACHE II Score/co-morbidities would still necessitate the admission to ICU.

In the current study patient selection for intrathecal morphine administration and subsequent admission to $\mathrm{HDU} / \mathrm{ICU}$ was influenced by bed occupancy, surgical procedure, emergent nature of the surgery and 
patients' pre-operative condition.

As such patients' of higher ASA grade were more commonly selected due to their perceived higher postoperative requirements and increased benefit from ITM versus intravenous opioid, with those deemed to have lower post operative requirements, in times of restricted HDU/ICU availability, being denied the analgesic effects due to lack of sufficient post-operative monitoring practices on general surgical wards. Be that as it may the patients here in would most likely required HDU/ICU admission postoperatively based on their higher ASA and subsequent higher APACHE scores. Restrictions to monitoring at ward level in the postoperative period, as well as the current application of the INEWS criteria and its implications, are obstacles to ward level care for these patients and as such curtails to use of this technique. If however these were overcome, by means of an acute pain team or similar services which would cater for the increased requirements of these patients and represent an added layer of care at ward level, patient selection would be paramount to its success. Elective procedures carried out on patients with lower ASA and APACHE would be most eligible. With the use of lower doses of ITM $(\leq 300 \mathrm{mcg})$ and the installation of an acute pain service at ward level to cater for these patients ward level roll out of postoperative care for ITM recipients could be possible.

The limited access to critical care beds locally (3), nationally (36) and internationally (37), creates many non-clinical challenges for the anaesthesiologists, surgeons and nursing staff. The lack of access to a critical care bed for scheduled or unscheduled surgery creates a demand-resource bottle neck and results in undue pressure on clinicians (38). Similar issues have previously been noted in relation to the administration of epidural analgesia (3) in our institution. Higher bed number and dedicated surgical beds, are potential solutions, however, in times of austerity the solution must be found in effective utilisation of existing infrastructure and human resources while concurrently improving standards of care. This may include change of practice and admission of selected patients, whom received $>300 \mathrm{mcg}$ of ITM, to general surgical wards.

The limitations of this study include the Small cohort analysed, the single-centred and retrospective nature of the study. The possibility of skewed outcomes due to selection criteria of patients as a result of ICU capacity issues also limit its interpretation.

In an effort to increase to extend the postoperative care of these patients past the doors of the ICU and onto the general wards in the hope of abolishing ICU capacity issues as a limiting factor in our ability to offer ITM to those who will benefit immensely from it, further work related to the postoperative INEWS scoring profile of patients administered with a lower dose of ITM $(<300 \mathrm{mcg})$ would be of great benefit to elucidate the safe common ground between efficacy and acceptable side effect profile.

\section{Conclusions}

In the current study we have displayed that patients receiving ITM can and will exhibit high EWS Scores which, if the patient is located on a level 1 ward, would initiate protocols as outlined by the INEWS scoring system in place. This may prove overly burdensome on wards ill-equipped to deal with patients requiring 
such high levels of attention and as such would not prove to be in the patients' best interest. However, these higher scores as evidenced herein may well be attributed to the relatively high dosing of ITM observed in this study, or possibly as an interaction between this dose and the cohort selected due to the pressure on ICU resources.

\section{Abbreviations}

ITM

Intrathecal Morphine

\section{Declarations}

\section{Ethical Approval}

Ethical Approval was granted by The Research Ethics Committee at Sligo University Hospital,Ireland.

\section{Consent for publication}

Not Applicable

\section{Availability of data and material}

Please contact author for data requests

\section{Competing interests}

The authors declare that they have no competing interests

\section{Funding}

No funding was sought or received in relation to this study.

\section{Author Contributions}

JRS collected and analysed data and drafted the manuscript

WRJ devised the study, aided with data analysis and drafted the manuscript

\section{Acknowledgements}

Not applicable

\section{References}


1. Rodgers A, Walker N, Schug S, McKee A, Kehlet H, van Zundert A, et al. Reduction of postoperative mortality and morbidity with epidural or spinal anaesthesia: results from overview of randomised trials. Bmj. 2000;321(7275):1493.

2. Practice Guidelines for the Prevention. Detection, and Management of Respiratory Depression Associated with Neuraxial Opioid Administration: An Updated Report by the American Society of Anesthesiologists Task Force on Neuraxial Opioids and the American Society of Regional Anesthesia and Pain Medicine. Anesthesiology. 2016;124(3):535-52.

3. Mullins C, O'Loughlin L, Albus U, Skelly JR, Smith J. Managing epidural catheters in critical care beds: An observation analysis in the Republic of Ireland. J Perioper Pract. 2018:1750458918808153.

4. Giovannelli M, Bedforth N, Aitkenhead A. Survey of intrathecal opioid usage in the UK. Eur J Anaesthesiol. 2008;25(2):118-22.

5. Gehling M, Tryba M. Risks and side-effects of intrathecal morphine combined with spinal anaesthesia: a meta-analysis. Anaesthesia. 2009;64(6):643-51.

6. Gehling MH, Luesebrink T, Kulka PJ, Tryba M. The effective duration of analgesia after intrathecal morphine in patients without additional opioid analgesia: a randomized double-blind multicentre study on orthopaedic patients. Eur J Anaesthesiol. 2009;26(8):683-8.

7. Brill S, Gurman GM, Fisher A. A history of neuraxial administration of local analgesics and opioids. Eur J Anaesthesiol. 2003;20(9):682-9.

8. Staikou C, Paraskeva A. The effects of intrathecal and systemic adjuvants on subarachnoid block. Minerva Anestesiol. 2014;80(1):96-112.

9. Sivevski AG, Karadjova D, Ivanov E, Kartalov A. Neuraxial Anesthesia in the Geriatric Patient. Front Med (Lausanne). 2018;5:254.

10. Cheah JW, Sing DC, Hansen EN, Aleshi P, Vail TP. Does Intrathecal Morphine in Spinal Anesthesia Have a Role in Modern Multimodal Analgesia for Primary Total Joint Arthroplasty? J Arthroplasty. 2018;33(6):1693-8.

11. Stamenkovic D, Geric V, Djordjevic M, Raskovic J, Slavkovic Z, Randjelovic T, et al. Subarachnoid morphine, bupivacaine and fentanyl as part of combined spinal-epidural analgesia for low anterior resection. A prospective, randomised, double-blind clinical trial. Anaesth Intensive Care. 2009;37(4):552-60.

12. Fleron MH, Weiskopf RB, Bertrand M, Mouren S, Eyraud D, Godet G, et al. A comparison of intrathecal opioid and intravenous analgesia for the incidence of cardiovascular, respiratory, and renal complications after abdominal aortic surgery. Anesth Analg. 2003;97(1):2-12. table of contents.

13. Koning MV, Teunissen AJW, van der Harst E, Ruijgrok EJ, Stolker RJ. Intrathecal Morphine for Laparoscopic Segmental Colonic Resection as Part of an Enhanced Recovery Protocol: A Randomized Controlled Trial. Reg Anesth Pain Med. 2018;43(2):166-73.

14. Mehta Y, Kulkarni V, Juneja R, Sharma KK, Mishra Y, Raizada A, et al. Spinal (subarachnoid) morphine for off-pump coronary artery bypass surgery. Heart Surg Forum. 2004;7(3):E205-10. 
15. Patel N, Bryant A, Duncan K, Kukreja P, Powell MF. Cost comparison of intrathecal morphine to intravenous patient-controlled analgesia for the first $24 \mathrm{~h}$ post cesarean delivery: a retrospective cohort study. J Anesth. 2017;31(1):44-50.

16. Sultan P, Gutierrez MC, Carvalho B. Neuraxial morphine and respiratory depression: finding the right balance. Drugs. 2011;71(14):1807-19.

17. Meylan N, Elia N, Lysakowski C, Tramer MR. Benefit and risk of intrathecal morphine without local anaesthetic in patients undergoing major surgery: meta-analysis of randomized trials. $\mathrm{Br} \mathrm{J}$ Anaesth. 2009;102(2):156-67.

18. Liu N, Kuhlman G, Dalibon N, Moutafis M, Levron JC, Fischler M. A randomized, double-blinded comparison of intrathecal morphine, sufentanil and their combination versus IV morphine patientcontrolled analgesia for postthoracotomy pain. Anesth Analg. 2001;92(1):31-6.

19. Joshi GP, Bonnet F, Kehlet $H$. Evidence-based postoperative pain management after laparoscopic colorectal surgery. Colorectal Dis. 2013;15(2):146-55.

20. Bauchat JR, McCarthy R, Fitzgerald P, Kolb S, Wong CA. Transcutaneous Carbon Dioxide Measurements in Women Receiving Intrathecal Morphine for Cesarean Delivery: A Prospective Observational Study. Anesth Analg. 2017;124(3):872-8.

21. Rathmell JP, Lair TR, Nauman B. The role of intrathecal drugs in the treatment of acute pain. Anesth Analg. 2005;101(5 Suppl):30-43.

22. Alhashemi JA, Sharpe MD, Harris CL, Sherman V, Boyd D. Effect of subarachnoid morphine administration on extubation time after coronary artery bypass graft surgery. $\mathrm{J}$ Cardiothorac Vasc Anesth. 2000;14(6):639-44.

23. Aun C, Thomas D, St John-Jones L, Colvin MP, Savege TM, Lewis CT. Intrathecal morphine in cardiac surgery. Eur J Anaesthesiol. 1985;2(4):419-26.

24. Boezaart AP, Eksteen JA, Spuy GV, Rossouw P, Knipe M. Intrathecal morphine. Double-blind evaluation of optimal dosage for analgesia after major lumbar spinal surgery. Spine (Phila Pa 1976). 1999;24(11):1131-7.

25. El-Hakeem. Effect of subarachnoid morphine administration on haemodynamic stress and extubation time after valve replacement surgery.. <st1:country-region style="font-size: 12.8px; background-color: $\operatorname{rgb}(255,255,255) ; "$ w:st="on"><st1:place w:st="on">Egypt</st1:country-region > J Anaesth 2003. p. 9-19

26. Fitzpatrick GJ, Moriarty DC. Intrathecal morphine in the management of pain following cardiac surgery. A comparison with morphine i.v. Br J Anaesth. 1988;60(6):639-44.

27. Hassett P, Ansari B, Gnanamoorthy P, Kinirons B, Laffey JG. Determination Of The Efficacy And Sideeffect Profile Of Lower Doses Of Intrathecal Morphine In Patients Undergoing Total Knee Arthroplasty. BMC Anesthesiol. 2008;8:5.

28. de Morais BS, Silva YP, Cruvinel MG, de Castro $\mathrm{CH}$, Hermeto MV. Accidental subarachnoid administration of $4 \mathrm{mg}$ of morphine. Case report. Rev Bras Anestesiol. 2008;58(2):160-4. 
29. Saxena AKAS. Current concepts in neuraxial administration of opioids and non-opioids: and overview and future perspectives. 2004;48:13-24.

30. Ko S, Goldstein DH, VanDenKerkhof EG. Definitions of "respiratory depression" with intrathecal morphine postoperative analgesia: a review of the literature. Can J Anaesth. 2003;50(7):679-88.

31. Health Service Executive. Guiding Framework and Policy for the National Early Warning Score System to Recognise. and Respond to Clinical Deterioration. 2019 [Available from:

https://www.hse.ie/eng/about/who/onmsd/practicedevelopment/mews/ewsframework.pdf.

32. Health Service Executive. Irish National Early Warning System (INEWS) Version 22021 [Available from: https://www.hse.ie/eng/about/who/cspd/ncps/deteriorating-patient-improvementprogramme/early-warning-systems/.

33. Kaufner L, Heimann S, Zander D, Weizsacker K, Correns I, Sander M, et al. Neuraxial anesthesia for pain control after cesarean section: a prospective randomized trial comparing three different neuraxial techniques in clinical practice. Minerva Anestesiol. 2016;82(5):514-24.

34. Abboud TK, Dror A, Mosaad P, Zhu J, Mantilla M, Swart F, et al. Mini-dose intrathecal morphine for the relief of post-cesarean section pain: safety, efficacy, and ventilatory responses to carbon dioxide. Anesth Analg. 1988;67(2):137-43.

35. Abouleish E, Rawal N, Rashad MN. The addition of $0.2 \mathrm{mg}$ subarachnoid morphine to hyperbaric bupivacaine for cesarean delivery: a prospective study of 856 cases. Reg Anesth. 1991;16(3):13740.

36. Rhodes A, Ferdinande P, Flaatten H, Guidet B, Metnitz PG, Moreno RP. The variability of critical care bed numbers in Europe. Intensive Care Med. 2012;38(10):1647-53.

37. Ward NS, Chong DH. Critical Care Beds and Resource Utilization: Current Trends and Controversies. Semin Respir Crit Care Med. 2015;36(6):914-20.

38. Fowler AL, Cullivan O, Sibartie S, O'Shea A, Waldron R, Khan I, et al. Utilisation of critical care services for surgical patients in a model three hospital. Ir J Med Sci. 2019.

\section{Tables}

Due to technical limitations, table 1 is only available as a download in the Supplemental Files section.

\section{Figures}




\section{4 patients}

$\longrightarrow$\begin{tabular}{c|}
104 patients were excluded: \\
$\cdot 38$ - Post-op Caesarean section patients \\
$\cdot 63$ - Received intrathecal fentanyl only \\
$\cdot 3$ - Received epidural opioids
\end{tabular}

\section{0 patients met the inclusion criteria.}

\section{Figure 1}

Exclusion Criteria outlines the exclusion criteria and number of patients excluded in relation to each.

\section{Breakdown of NEWS Scores}

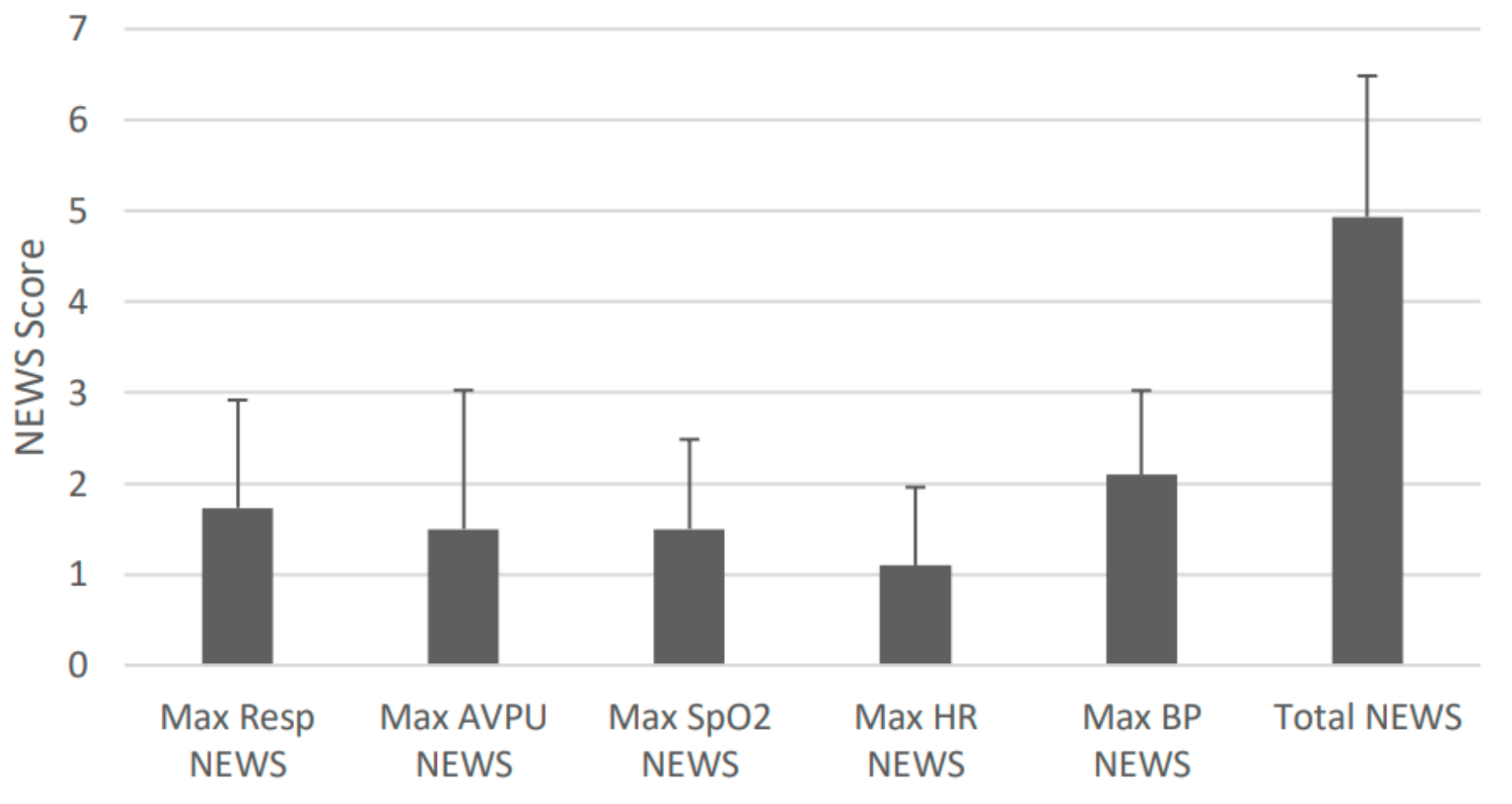

Figure 2

presents the Mean $\pm S D$ for each constituent of the EWS score as well as that of the total EWS score. 


\begin{tabular}{|c|c|c|c|c|c|c|c|}
\hline SCORE & 3 & 2 & 1 & 0 & 1 & 2 & 3 \\
\hline $\begin{array}{l}\text { Respiratory } \\
\text { Rate (bpm) }\end{array}$ & $\leq 8$ & & $9-11$ & $12-20$ & & $21-24$ & $\geq 25$ \\
\hline $\mathrm{SpO}_{2}(\%)$ & $\leq 91$ & $92-93$ & $94-95$ & $\geq 96$ & & & \\
\hline $\begin{array}{l}\text { Inspired } 02 \\
\text { (FiO2) }\end{array}$ & & & & Air & & & Any $\mathrm{O}_{2}$ \\
\hline $\begin{array}{l}\text { Systolic BP } \\
\text { (mmHg) }\end{array}$ & $\leq 90$ & $91-100$ & $101-110$ & $111-249$ & $\geq 250$ & & \\
\hline $\begin{array}{l}\text { Heart Rate } \\
\text { (bpm) }\end{array}$ & & $\leq 40$ & $41-50$ & $51-90$ & $91-110$ & $111-130$ & $\geq 131$ \\
\hline AVPU & & & & Alert (A) & & & $\begin{array}{l}\text { Voice }(\mathrm{V}) \text {, Pain }(\mathrm{P}) \text {, } \\
\text { Unresponsive }(\mathrm{U})\end{array}$ \\
\hline
\end{tabular}

\section{Figure 3}

Irish National Early Warning System (INEWS) chart Scoring system Adapted from the Irish National Early Warning System (NEWS) chart [31] 


\begin{tabular}{|c|c|c|c|}
\hline Total Score & $\begin{array}{l}\text { Minimum } \\
\text { Obsenvation } \\
\text { Frequency } \\
\text { (Hours) }\end{array}$ & Alert & Response \\
\hline 1 & 12 hourly & Nurse in Charge & 1. Nurse in Charge to review if new onset score 1 \\
\hline 2 & 6 hourly & Nurse in Charge & 1. Nurse in Charge to review \\
\hline 3 & 4 hourly & Nurse in Charge + Team/SHO & 1. $\geq \mathrm{SHO}$ to review in 1 hour \\
\hline $4-6$ & 1 hourly & Nurse in Charge $+\mathrm{Team} / \mathrm{SHO}$ & $\begin{array}{l}\text { 1. } \geq \text { SHO to review in } 1 / 2 \text { hour } \\
\text { 2. Screen for sepsis } \\
\text { 3. If no response in } 1 \text { hour, contact Registrar } \\
\text { 4. Consider continuous monitoring } \\
\text { 5. Consider transfer to higher level care }\end{array}$ \\
\hline$\geq 7$ & $1 / 2$ hourly & $\begin{array}{l}\text { Nurse in Charge + } \\
\text { Registrar/Consultant }\end{array}$ & $\begin{array}{l}\text { 1. Registrar to review immediately } \\
\text { 2. Continuous monitoring recommended } \\
\text { 3. Plan to transfer to hight level care } \\
\text { 4. Activate emergency response system }\end{array}$ \\
\hline \multicolumn{4}{|c|}{ NOTE: Single Score Triggers } \\
\hline $\begin{array}{l}\text { Score of } 2 \text { in any } \\
\text { single parameter } \\
\qquad H R \leq 40\end{array}$ & $1 / 2$ hourly & Nurse in Charge $+\mathrm{Team} / \mathrm{SHO}$ & 1. SHO to review immediately \\
\hline $\begin{array}{l}\text { Score of } 3 \text { in any } \\
\text { single parameter }\end{array}$ & $1 / 2$ hourly & Nurse in Charge + Team $/ \mathrm{SHO}$ & $\begin{array}{l}\text { 1. SHO to review immediately } \\
\text { 2. If no response to treatment contact Registrar } \\
\text { 3. Activate emergency response system }\end{array}$ \\
\hline
\end{tabular}

\section{Figure 4}

Irish National Early Warning Score Escalation Protocol

\section{Supplementary Files}

This is a list of supplementary files associated with this preprint. Click to download.

- ITMTable1.pdf 